Mens

revue d'histoire intellectuelle de l'Amérique française

Gaétan Gervais. Des gens de résolution. Le passage du

"Canada français " à l'" Ontario français ". Sudbury, Éditions Prise de parole, 2003. 230 p.

\title{
Paul Dubé
}

Volume 7, numéro 1, automne 2006

URI : https://id.erudit.org/iderudit/1024233ar

DOI : https://doi.org/10.7202/1024233ar

Aller au sommaire du numéro

Éditeur(s)

Centre de recherche en civilisation canadienne-française

ISSN

1492-8647 (imprimé)

1927-9299 (numérique)

Découvrir la revue

Citer ce compte rendu

Dubé, P. (2006). Compte rendu de [Gaétan Gervais. Des gens de résolution. Le passage du " Canada français » à l'« Ontario français ». Sudbury, Éditions Prise de parole, 2003. 230 p.] Mens, 7(1), 172-178. https://doi.org/10.7202/1024233ar d'utilisation que vous pouvez consulter en ligne.

https://apropos.erudit.org/fr/usagers/politique-dutilisation/ 


\section{Gaétan Gervais. Des gens de résolution. Le passage du "Canada français » à l'» Ontario français ». Sudbury, Éditions Prise de parole, 2003. 230 p.}

Comme l'explique l'auteur à la fin de son introduction, "les "gens de résolution", ce sont les premiers Français venus prendre possession du bassin des Grands-Lacs au XVII siècle, mais aussi leurs lointains héritiers qui perpétuent en Ontario la langue et la culture françaises, mais dans son expression franco-ontarienne » (p. 15). Cet heureux et judicieux vocable pour l'histoire qu'on nous présente ici trouve son origine chez l'intendant Jean Talon qui l'a utilisé pour qualifier ces premiers pionniers installés dans ladite région, choix qui "préfigurait en quelque sorte le futur entêtement des communautés françaises» (p. 7) en Ontario, dont l'histoire, on s'en doute, ressemble beaucoup à celle des autres provinces du Canada français.

Le volume est divisé en trois grands chapitres. Ceux-ci définissent clairement les questions discutées et les sources auscultées sur lesquelles s'est construite la narration des faits, les événements, les pensées, les discours, etc., démarquant les grandes étapes dans la mouvance identitaire francoontarienne suivant la transformation soulignée dans le soustitre : "L'Ontario français et les grands congrès patriotiques canadiens-français (1883-1952) »; "L’Ontario français et les "États généraux du Canada français" (1966-1969 »; «Aux origines de l'identité franco-ontarienne ». L'historien Gaétan Gervais s'attaque donc à ces trois grands moments, soit dans un premier temps à la tradition canadienne-française qui remonte au début du Canada comme nation - où il était encore possible de poser l'existence d'un Canada français a mari usque ad mare -, dans un deuxième temps à l'affirmation québécoise, période des années soixante qui a vu l'effondrement de ce Canada français dans le sillon d'un Québec dorénavant 
tourné sur lui-même dans son affirmation politique, et dans un troisième temps à l'époque suivant le divorce consommé à la dernière rencontre des États généraux en mars 1969 qui marque le début de la (dé)marche vers la nouvelle identité franco-ontarienne.

Dans le premier chapitre qui traite surtout de la période de 1883 à 1952, Gervais expose d'abord la « culture de congrès » qui imprègne et dont se nourrissent les communautés françaises de la période, en racontant comment et pourquoi les premières " conventions » ont vu le jour aux ÉtatsUnis, au Québec et en Acadie. Il y précise l'apport des différents regroupements ou organismes comme l'Ordre de Jacques-Cartier, ou La Patente, et la Société Saint-Jean-Baptiste, pour ne mentionner que ceux-là. On y retrouve partout, cela va de soi dans le contexte des maîtres d'œuvre officiant à ces manifestations (surtout le clergé), une communion de pensée et d'intérêt, notamment " une origine française commune, un attachement à la langue et à la culture françaises, (et) une communauté de foi » (p. 21). L'auteur choisit cette documentation en raison du fait que «l'unité de la pensée canadiennefrançaise [...] se manifesta rarement avec plus d'éclats [sic] que lors des dizaines de congrès, tant patriotiques que religieux, qui ponctuèrent l'histoire de la nation canadienne-française » (p. 18).

Cette mise en situation nous prépare à la description fouillée des trois grands congrès tenus à Québec, le « berceau » de l'Amérique française, en 1912, 1937 et 1952, tous les trois animés par le "même dessein» (p. 63). Relevant à la fois du "pèlerinage religieux, du rassemblement patriotique, de la fête populaire et du congrès scientifique ", "représentant toutes les communautés françaises du continent » (p. 62), minutieusement préparés et faisant l'objet d'intenses campagnes publicitaires, ces congrès célèbrent les retrouvailles de la grande 
famille canadienne-française "venue ausculter ensemble la santé de la langue et de la culture françaises en Amérique, surtout au Canada » (p. 63). Pour que rien ne soit perdu de ces rencontres, on produit des volumes rapportant in extenso tout ce qui avait été dit : études, discours, communications, interventions, remerciements, hommages de toutes sortes qui « méritent donc qu'on les tienne pour l'expression réfléchie [des] idées et [des] valeurs [des] élites canadiennes-françaises " (p. 63) de l'époque. Avec force détails, Gervais nous mène dans les coulisses des longs préparatifs et des communications entre les organisateurs, intervenants de tout acabit, présidents d'associations, chefs locaux, directeurs d'école et ainsi de suite, en fait, une petite armée de "gens engagés » qui vaquent diligemment à l'opération qui se prépare. Un véritable tour de force quand on songe aux moyens dont on disposait à l'époque...

C'est ainsi qu'on peut suivre, se manifestant toujours dans une grande unité, l'évolution des dossiers, de certaines pensées, des idéologies, etc. : par exemple, la façon dont la pensée de Groulx - qui avance un nationalisme "moins triomphaliste, plus militant, axé sur le Canada français» (p. 74) - en est venue à supplanter celle de Bourassa, comment au fil des ans et en dépit des perturbations ponctuelles, l'identité se précise tout en restant « dans la parfaite continuité idéologique » (p. 87). En fin de compte, comme le rapporte l'auteur, ces trois grands congrès "procèdent d'une certaine unité de pensée » où se révèle la "vision du monde » que partagèrent les élites du Canada français, ainsi énoncée dans les paroles de $\mathrm{M}^{\mathrm{gr}}$ Maurice Baudoux, archevêque de Saint-Boniface, en 1952 : « Notre communauté d'origine et d'histoire ; notre communauté de langue, expression de notre culture particulière ; notre communauté de croyance et de vie surnaturelle ; enfin notre communauté d'aspiration vers un idéal qui s'élève au- 
dessus des contingences matérielles" (p. 17). Un fantasme d'harmonie et d'unité semble se maintenir encore dans les années $1950 \ldots$

Comme quelques événements peuvent changer le monde! Car dans la première phrase du deuxième chapitre, Gervais nous amène d'entrée de jeu à la conclusion de cet épisode, à savoir que les trois réunions des États généraux $d u$ Canada français entre 1966 et 1969, constituent, en fait, «le dernier acte de l'histoire du nationalisme canadien-français » (p. 107). Du point de vue du lecteur, c'est nettement le chapitre le plus palpitant puisqu'il dévoile toute la politicaillerie qui sévit dans ce genre de débandade collective où les complicités d'antan se défont et se départissent suivant la logique des plus forts et des plus faibles. L'auteur narre dans ce chapitre l'histoire du « rejet du fédéralisme canadien par une partie grandissante du mouvement nationaliste [qui] étouffa le nationalisme canadien-français et assura le passage d'un nationalisme catholique, basé sur l'idée du Canada français, à un nationalisme québécois, défini par une appartenance territoriale » (p. 108).

En effet, les quelque cent ans d'unanimité ont vite fait place en une douzaine d'années (au cours desquelles meurt Duplessis) à une transformation de la dynamique entre le Québec et les communautés du Canada français. C'est tôt dans ce chapitre qu'on voit apparaitre certaines figures importantes du futur mouvement souverainiste, notamment le juriste et futur ministre péquiste Jacques-Yvan Morin. Très tôt, on peut déjà apprécier tout le chemin parcouru dans l'affirmation politique québécoise ; très tôt, soit avant même la première rencontre, les jeux sont faits, semble-t-il : on parle d'une Confédération canadienne "périmée » (p. 114) ainsi que de la possibilité d'une Constituante pour le Québec, l'Ordre de Jacques-Cartier est dissous dès février 1965 et on parle de Cana- 
diens français "d'outre-frontière ». De dire Gervais, "le muselage des minorités semble [...] avoir fait partie d'une stratégie » (p. 123) des premiers instants, entre autres, par le niveau de participation proposé aux délégués non québécois et les droits de vote accordés selon les questions débattues. Dans ce contexte où les dés semblent pipés, l'Ontario français officiel décide de se retirer de la troisième rencontre de 1969, car on juge futile une participation dont le point de départ accuse déjà la scission et impose des objectifs différents aux parties : "Nous pensons que nos compatriotes des autres provinces seront plus heureux de rechercher des solutions à leurs problèmes que de s'appliquer à régler ceux du Québec » (p. 172), comme l'annonce l'organisateur en chef. En fin de compte, Gervais résume ce qu'il a démontré en détail avec verve et une amertume certaine dans ce chapitre : "Aux États généraux, on tenta de museler les minorités, on les empêcha de se prononcer sur les dossiers constitutionnels, on leur attribua une place de second rang, on les traita avec condescendance et paternalisme. [...] ; les minorités finirent par reconnaître que leur rôle de figurant servait de caution morale à des machinations politiques orientées vers la séparation du Québec » (pp. 190-191). Et de conclure l'auteur : «Les États généraux n'ont ni causé ni précipité la fin du Canada français, ils en apportèrent seulement une preuve éloquente » (p. 191).

Le troisième chapitre - «Aux origines de l'identité franco-ontarienne " - revoit rapidement, dans un premier temps, les faits saillants de l'histoire qui ont mené à la " rupture tranquille », aboutissant dans l'optique de Gervais à deux grands ressentiments pour les minorités françaises de l'Ontario (et du pays, cela va de soi) : «l'exclusion (les indépendantistes étant désormais les seuls purs) et la dépossession (la "québécisation" de la culture canadienne-française, processus culturel par lequel la "culture québécoise" s'appropri[e] 
tout le bien culturel commun» (p. 196). Les affligeants dead ducks (René Lévesque) et "cadavres encore chauds" (Yves Beauchemin) accolés aux cousins d'hier témoignent de la rupture voulue et de l'éclatement du référent ancien, et restent des signes éloquents du divorce, phénomènes qui suscitent un repositionnement identitaire. Voilà ce que Gervais analyse dans la deuxième partie de ce dernier chapitre où il suit la dynamique du "questionnement sur l'identité francoontarienne » jusqu'à la "nouvelle direction » que se donne l'Ontario français. Un processus auquel d'aucuns peuvent s’identifier dans le nouveau Canada français...

Quelques remarques en guise de conclusion. Les trois grands chapitres du livre ont paru séparément dans les $C a$ biers Charlevoix. Études franco-ontariennes en 1997, 1998 et 1995 respectivement. Ce qui veut dire qu'il y a référence dans ce texte à des études qualifiées de "récentes ", mais qui, cependant, datent de quinze ans dans certains cas. Il y a donc absence d'études récentes qui seraient pertinentes. Cette déficience se fait surtout sentir au chapitre consacré à la problématique identitaire, très actuelle dans la mouvance d'une immigration dite «multiculturelle francophone » de plus en plus déterminante pour les communautés du Canada français.

Mais la lacune la plus significative dans cet essai est l'absence d'une mise en contexte des cadres dans lesquels s'insère le Canada français pendant la période étudiée. La mort de Duplessis, la Révolution tranquille, les slogans des gouvernements Lesage en tant que signes d'une nouvelle dynamique, etc. : tout cela est passé sous silence dans ces pages. Pensons également à l'année 1968, l'année qui suit les fêtes du centenaire de la Confédération, durant laquelle les recommandations de la Commission sur le bilinguisme et le biculturalisme commencent à modifier la donne publique sur les relations entre francophones et anglophones ; c'est celle égale- 
ment durant laquelle se joue le dernier acte dans le processus de «séparation » entre le Québec et le Canada français : nulle mention de Trudeau et de la fameuse "trudeaumanie » des élections, et de tout ce que cela a pu soulever d'espoir pour défaire les deux vieilles solitudes... La pertinence de tout cela ?

Aux lecteurs et lectrices de juger si ces quelques réserves valent d'être mentionnées. Elles ont été significatives pour moi. Cela dit, il n'existe sans doute aucune étude aussi exhaustive qui témoigne si clairement par le menu détail de la rupture quand même assez soudaine (une meilleure mise en contexte aurait peut-être donné une autre impression) entre le Québec et les communautés francophones du Canada. Ces dernières, d'ailleurs, ont réussi à éviter le naufrage anticipé, même souhaité... Il faut sans doute plus que cela pour liquider des « gens de résolution »...

\title{
Paul Dubé Department of Modern Languages and Cultural Studies Université de l'Alberta
}

\begin{abstract}
Nicole Racine et Michel Trebitsch, dir. Intellectuelles. Du genre en histoire des intellectuels. Bruxelles, Éditions Complexe, 2004. 347 p. (Coll. « Histoire du temps présent »).
\end{abstract}

L'idée première de ce recueil date d'une dizaine d'années. Les deux codirecteurs du Groupe de recherche sur l'histoire des intellectuels (GRHI, Paris), Nicole Racine et Michel Trebitsch, ayant souhaité des enquêtes exploratoires en vue d'un ouvrage sur les intellectuelles, les premiers travaux prirent la forme d'une table ronde, en 1997-98, avec la participation de Françoise Collin, Michelle Perrot et Florence Ro- 